\title{
Mukopolisakkaridozlarda omurga sorunları
}

\section{Spinal problems in mucopolysaccharidoses}

\author{
Şenol Bekmez ${ }^{1}$, Muharrem Yazıcı ${ }^{2}$ \\ ${ }^{1}$ Özel Çankaya Hastanesi, Ortopedi ve Travmatoloji Departmanı, Ankara \\ ${ }^{2}$ Hacettepe Üniversitesi Tıp Fakültesi, Ortopedi ve Travmatoloji Anabilim Dalı, Ankara
}

Mukopolisakkaridozlarda, glukozaminoglikanların hücre içi lizozomal degredasyonlarında rol oynayan enzimler doğuştan eksiktir. Bu eksiklik glukozaminoglikanların proteinlerinin dokularda anormal birikimine neden olmaktadır. Mukopolisakkaridozlu hastalarda birçok organ ve sistemle birlikte, kas-iskelet sistemi de hastalıktan etkilenir. Atlantoaksiyel instabilite, servikal spinal stenoz ve torakolomber bileşkede gibbus deformitesi, mukopolisakkaridozun karakteristik omurga bulgularını oluşturmaktadır. Son yıllarda enzim replasmanı ve kemik iliği transplantasyonu tedavilerindeki ilerlemeler sayesinde, mukopolisakkaridozlu hastaların beklenen hayat süreleri artmıştır. Bu nedenle, omurga tutulumu ve diğer kas iskelet sistem tutulumu sonucu oluşan bozuklukların tedavisi, mukopolisakkaridozlu hastaların fonksiyonel kapasitelerini ve hayat kalitelerini yükseltmede kritik rol oynamaktadır.

Anahtar sözcükler: mukopolisakkaridoz; torakolomber gibbus; lizozomal depo hastalığı
In mucopolysaccharidosis, the enzymes involved in intracellular lysosomal degradation of glycosaminoglycans are congenitally lacking. This deficiency leads to abnormal accumulation of glucosaminoglycans' proteins in the tissues of the patient. In patients having mucopolysaccharidosis, musculoskeletal system is also affected by the disease, besides multiple organs and the system. Atlantoaxial instability, spinal stenosis, and thoracolumbar junction gibbus deformity constitute the characteristic mucopolysaccharidosis findings of the spine. In recent years, the expected life span of patients with mucopolysaccharidoses has increased, thanks to the advances of enzyme replacement therapy and bone marrow transplantation. Consequently, the treatment of disorders resulting from the involvement of the spine and the musculoskeletal system, plays a critical role in improving the functional capacity and quality of life of mucopolysaccharidosis patients.

Key words: mucoploysaccharidosis; thoracolumbar gibbus; lysosomal storage disease

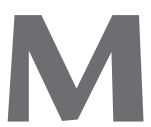

ukopolisakkaridozlar (MPS), nadir görülen bir genetik hastalık olup insidansı yaklaşık 25 bin canlı doğumda bir olarak bildirilmiştir. ${ }^{[1]}$ Bağ dokusunun önemli bir bileşeni olan glikozaminoglikanların (GAG) yıkımından sorumlu lizozomal enzimler, doğumsal olarak eksiktir. Bu nedenle GAG'lar hücre içinde anormal düzeyde birikir (Tablo 1). Bu anormal birikim sonucu büyüme plağı mimarisi bozulurken, ikincil inflamatuvar reaksiyonlar nedeniyle, ilerleyici hücresel işlev bozuklukları ortaya çıkmaktadır. ${ }^{[2]}$

MPS'li hastalarda doğumda herhangi bir klinik bulgu gözlenmezken, ilk kognitif ve somatik bulgular emekleme döneminin sonuna doğru ortaya çıkar. GAG'ların anormal hücre içi birikimi birçok organ ve sistemin yapı ve işlevini etkiler (Tablo 2). Sonuç olarak, eksik enzimin tipine bağlı olarak, heparan sülfat, dermatan sülfat ve keratan sülfat gibi maddeler kondrositlerde, eklem kıkırdağının ekstrasellüler matriksinde, sinoviyumda ve bağlarda birikerek 'dizostosis multipleks' olarak olarak adlandırılan kas-iskelet sistemi bulgularını ortaya çıkarır.

\section{PATOFIZYOLOJi}

MPS'li hastalarda lizozomal GAG birikimi, hücresel düzeyde büyüme plaklarının mimarisini bozar. GAG birikintilerinin 'toll-like receptor 4' aracılığıla oluşturduğu inflamatuvar yanıt, ilerleyici hücre ve organ disfonksiyonuna neden olur. ${ }^{[3]}$ Biyopsi spesimenlerinde yapılan histolojik değerlendirmelerde, büyüme plaklarının normalden daha geniş olduğu, proliferatif ve hipertrofik zonların organizasyonlarının bozuk olduğu görülmüştür. Ayrıca, kondral mineralizasyonun meydana geldiği longitudinal septaların sayısının azalması sonucu, metafizlerde düzensizlik meydana gelir.

- İletişim adresi: Dr. Muharrem Yazıcı, Hacettepe Üniversitesi Tıp Fakültesi, Ortopedi ve Travmatoloji Anabilim Dalı, Sıhhiye, Ankara Tel: 0312 - 3051209 e-posta: mimyazici@gmail.com

- Geliş tarihi: 8 Ağustos $2016 \quad$ Kabul tarihi: 8 Ağustos 2016 
Tablo 1. Mukopolisakkaridoz sınıflandırması

\begin{tabular}{|c|c|c|c|c|}
\hline MPS & İsim & Biriken GAG & Enzim & Kalıtım \\
\hline I & Hurler & $\begin{array}{l}\text { Heparan S + } \\
\text { Dermatan S }\end{array}$ & Alfa iduronidaz & OR \\
\hline II & Hunter & $\begin{array}{l}\text { Heparan S + } \\
\text { Dermatan S }\end{array}$ & İduronat sulfataz & $\mathrm{XLR}$ \\
\hline III & $\begin{array}{l}\text { Sanfilippo } \\
\text { Tip A } \\
\text { Tip B } \\
\text { Tip C } \\
\text { Tip D }\end{array}$ & Heparan S & $\begin{array}{l}\text { Heparan sulfataz } \\
\mathrm{N} \text { asetilglukozaminidaz } \\
\text { AG asetiltransferaz } \\
\text { Asetilglukozamin 6-sulfataz }\end{array}$ & OR \\
\hline IV & $\begin{array}{l}\text { Morquio } \\
\text { Tip A } \\
\text { Tip B }\end{array}$ & $\begin{array}{l}\text { Keratan S } \\
\text { Kondroitin S }\end{array}$ & $\begin{array}{l}\text { Galaktoz } 6 \text { sulfataz } \\
\text { Beta galaktozidaz }\end{array}$ & OR \\
\hline V & Scheie & \multicolumn{3}{|c|}{ Illk başlarda Tip V olarak sınıflandırılmış ancak daha sonra Tip I spektrumuna dahil kabul edilmişsti } \\
\hline VI & Maroteaus-Lamy & Dermatan S & Arilsulfataz B & OR \\
\hline VII & Sly & $\begin{array}{l}\text { Heparan S + } \\
\text { Dermatan S }\end{array}$ & Beta glukoronidaz & OR \\
\hline
\end{tabular}

OR, Otozomal resesif; XLR, X-linked resesif.

Tablo 2. Mukopolisakkaridozlardaki organ tutulumları

\begin{tabular}{ll}
\hline Santral sinir sistemi & Hidrosefali \\
& Servikal miyelopati \\
\hline Kardiyovasküler sistem & Anjina \\
& Kalp kapakçık disfonksiyonu \\
& Hipertansiyon \\
& Konjestif kalp yetmezliği \\
& Uyku apnesi \\
Pulmoner sistem & Havayolu obstruksiyonu \\
& Kor pulmonale \\
& Glokom \\
Oftalmolojik ve işitsel & Retinal dejenerasyon \\
& Kronik papillödem \\
& Kornea tutulumu \\
& Sağırlık \\
& Inguinal herni \\
& Hepatosplenomegali \\
& Kısa boy \\
& Eklem kontraktürleri/hipermobilitesi \\
Abdominal & Tuzak nöropatiler \\
& Tetik parmak \\
& Kısa ve kalın falankslar \\
& Femur başı displazisi, koksa valga \\
& Genu valgum \\
& Odontoid hipoplazisi \\
& Platispondili \\
Kas-iskelet sistemi & Vertebrada anterior kamalaşma \\
& Torakolomber kifoz \\
& Kürek şeklinde kaburgalar \\
& Kısa ve kalınlaşmış klavikula \\
& \\
& \\
& \\
& \\
& \\
& \\
& \\
&
\end{tabular}

\section{TANI VE SISTEMIK TEDAVi}

MPS şüphesi olan ve genetik tanısı henüz konmamış olgularda kemik survey istenmelidir. Röntgen görüntülemesinde; kalça displazisi, klavikula ve kaburgalarda genişleme, radiusta Madelung deformitesi benzeri değişiklikler, kısa ulna, kafatasında genişleme, genu valgum, torakolomber gibbus deformitesi gibi iskelet bulguları gözlenir. MPS taramasında idrar GAG analizi yaygın şekilde kullanılmaktadır. Tarama testlerinde, MPS şüphesi bulunan olgularda beyaz küre ve fibroblastlarda enzim aktivitesi düzeyi saptanarak tanı kesinleştirilir. Taşıyıcılar ise mutasyon analizi veya azalmış enzim aktivitesinin gösterilmesi ile saptanabilir. ${ }^{[4]}$

Kemik iliği transplantasyonu ve enzim replasman tedavisindeki gelişmeler sonucu, MPS'li hastaların beklenen yaşam süreleri ve hayat kaliteleri anlamlı şekilde artmıştır. ${ }^{[5,6]}$ Ancak, sistemik tedavilerin kas iskelet sistemi bulguları üzerinde iyileştirici bir etkisi gösterilememiştir. Bu nedenle, MPS'li hastalarda ortopedik tedavi, hastaların fonksiyonel kapasitelerini ve hayat kalitelerini iyileştirebilmek adına, hala çok önemli bir yer tutmaktadır.

\section{MPS'DE OMURGA SORUNLARI}

MPS'deki omurga tutulumu oksipitoservikal instabilite, servikal stenoz, akut torakolomber kifoz ve skolyoz şeklinde meydana gelir.

\section{Servikal Stenoz}

Servikal spinal kord kompresyonu, MPS'li hastalarda ani ölümün en sık nedenidir. ${ }^{[7]}$ Özellikle oksipitoservikal 

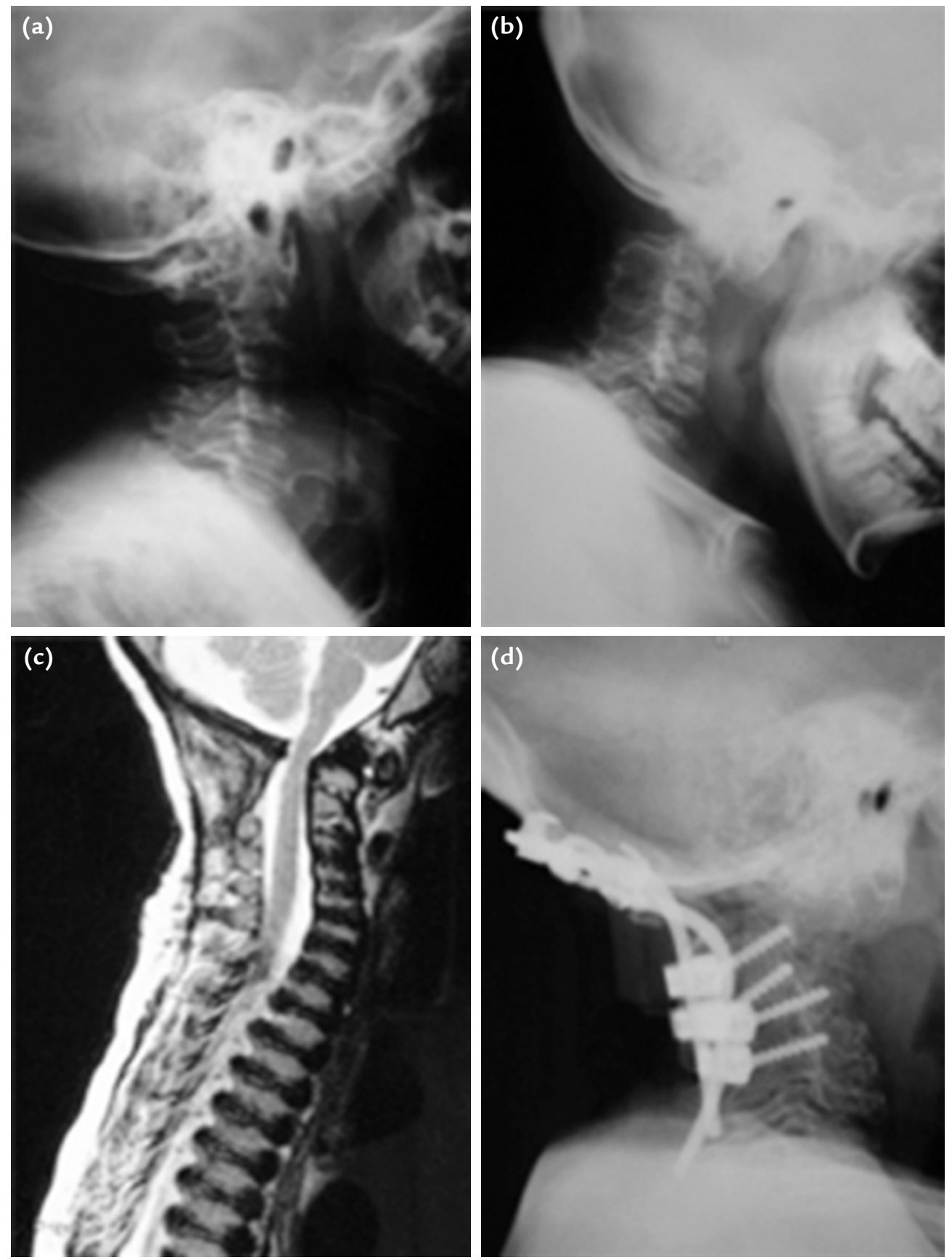

Şekil 1. a-d. MPS'li hastalarında atlantoaksiyel instabilitenin varlığı fleksiyon (a) ve ekstansiyon (b) grafileri ile ortaya konur. MR incelemesi okspitoservikal bileşkedeki stenozu göstermektedir (c). Tedavide dekompresyon ile birlikte oksipitoservikal füzyon önerilir (d).

bileşkede, odontoid proses etrafında glukozaminoglikan birikimi, dural kalınlaşma ve $\mathrm{C} 1$ vertebra hipoplazisi gibi etkenlerle, ilerleyici stenoz meydana gelir. Bu durum, özellikle Morquio sendromunda (MPS Tip IV), atlantoaksiyel instabilitenin eşlik etmesi nedeniyle daha da şiddetli bir hal alır. ${ }^{[8]}$ Bu hasta grubunda cerrahi endikasyonların sınırları net değildir. Sarsak yürüme, üst ve alt ekstremitelerde kuwetsizlik, dizestezi ve üriner retansiyon ciddi miyelopati bulgularıdır. ${ }^{[9,10]}$ Klinik bulguların yanında, radyolojik incelemelerde $8 \mathrm{~mm}$ 'den fazla instabilite, kord için gerekli alanın 14 mm'den az olması ve manyetik rezonans (MR) görüntülemede kord sinyal değişikliklerinin bulunması ciddi kord basısı tehdidi oluşturduğundan, cerrahi tedavi endikedir (Şekil 1). ${ }^{[11]}$ 
MPS'li hastalarda servikal omurga tutulumu en sık oksipitoservikal bileşkede izole stenoz şeklinde olduğundan, stabilizasyonsuz tek başına dekompresyon yeterli olmaktadır. Burada atlanmaması gereken husus, özellikle MPS Tip IV'te görülen atlantoaksiyel instabilitedir. Bu durumda, iyatrojenik instabiliteden kaçınmak için dekompresyona ilave olarak oksiputtan C2'ye uzanan füzyon ve gerekli durumlarda halo vest uygulaması önerilmektedir. ${ }^{[12]}$

MPS'de spinal stenozun diğer bir şekli dural kalınlaşmadır. Bu varyasyon en sık MPS Tip I ve VI'da gözlenir. Tedavi seçenekleri; çok seviyeli dekompresyon, laminoplasti ve durotomidir. ${ }^{[9]}$

\section{Torakolomber Kifoz}

Torakolomber kifoz MPS'nin erken gelişen bir bulgusu olup, özellikle MPS Tip I, II ve VI'da görülür. Patofizyolojisinde, kas hipotonisi, anterior disk prolapsı; vertebral uç plaklarının anormal ossifikasyon ve büyümesi, gibi etkenler rol oynar. ${ }^{[13]}$ Gibbus deformitesi olarak da adlandırılan akut kifotik deformite, genellikle L1-2 vertebralarda lokalizedir. ${ }^{[10]}$ Apikal vertebra anterioru kamalaşır ve vertebra posteriora yer değiştirir. Gibbus deformitesine skolyoz da eşlik edebilir. ${ }^{[10]}$ Lateral grafide apikal vertebradaki anterior 'gagalaşma' MPS açısından patognomoniktir. ${ }^{[14]}$ Apikal vertebranın bir üst ve bir altındaki disk mesafeleri korunur. Ayrıca, radyolojik çalışmalarda apikal vertebrada ve komşu disk segmentlerinde hipermobilite bulunduğu gösterilmiştir. ${ }^{[15]}$ Bu hipermobilitenin, GAG birikimine bağlı olarak, bağların mekanik özelliklerini yitirmesiyle oluştuğu düşünülmektedir. Yürüme çağından itibaren, yük taşıyıcı kuvvetler, apeksteki hipoplastik vertebrada retrolistezisi arttırırken gövdenin anteriora yer değiştirmesine neden olur. Gövde dengesini düzenlemek için torasik lordoz ve pelvik retroversiyon gibi kompansatuvar mekanizmalar da devreye girer.

Gibbus deformitesinin şiddeti çeşitlilik gösterirken, enzim replasman tedavisinin deformite üzerinde olumlu bir etkisi olmadığı gösterilmiştir. ${ }^{[5]}$ Özellikle MPS Tip I hastalarında $45^{\circ}$ 'den daha büyük deformitelerin ilerleyici olduğu bilinmektedir. Yetmiş derecenin üzerine çıkan ve miyelopatinin eşlik ettiği eğriliklerde cerrahi tedavi kesin olarak endikedir. ${ }^{[1,10]}$ MPS'li hastalarda gibbus deformitesine neden olan instabil ve hipermobil deformite apeksi ciddi bir kord basısı riski taşımakla birlikte, bu durumun gerçek insidansı bilinmemektedir. ${ }^{[16]}$

MPS kifozunda cerrahi tedavi yöntemi konusunda bir konsensüs bulunmamaktadır. Literatürde, küçük hasta gruplarına sahip az sayıda geriye dönük çalışma mevcuttur. Dalvie ve ark., yedi hastalık serilerinde anterior enstrümantasyon ve füzyonla başarılı sonuçlar bildirmiştir. ${ }^{[17]}$ Yakın tarihli çalışmalarda, kombine anterior ve posterior füzyonun daha popüler olduğu görülmektedir. Garrido ve ark., dört hastada kombine tekniğin listetik vertebranın redüksiyonunda ve stabilizasyonda etkin olduğunu vurgulamışlardır. ${ }^{[18]}$ Başka bir çalışmada ise Abelin-Genevios ve ark., 13 hastalık serilerinde $360^{\circ}$ füzyonun etkinliğini vurgularken, sadece posterior yaklaşımla cerrahi uyguladıkları hastalarda yüksek başarısızlık riski olduğunu belirtmişlerdir. ${ }^{[19]}$ Ancak, bu hastalar daha yakından incelendiğinde, posterior yaklaşımla tedavi edilen hastalarda uygulanan yöntemde kısa segment hook enstrümantasyonunun tercih edildiği görülmektedir. Literatürde, MPS kifoz cerrahisinde posterior yaklaşımla modern pedikül vidası sistemleri kullanımının sonuçlarını bildiren bir çalışma bulunmamaktadır. Bu konuda, kendi altı hastalık deneyimimizde, ortalama 52 aylık takip sonucunda apikal vertebranın proksimal ve distalinde en az ikişer seviyede olmak üzere posterior kolon osteotomisi ile birlikte posterior enstrümante füzyonun etkin ve güvenli olduğunu görülmüştür (Şekil 2). ${ }^{[20]}$

MPS kifozlarının cerrahi tedavisinde en büyük problemlerden biri, komşu segmentlerde gelişen sekonder deformitelerdir (Şekil 3). İskelet displazisi bulunan hastalarda, posterior enstrümantasyon ve füzyon tedavisinden sonra yüksek oranda proksimal bileşkede kifoz görüldüğü bilinmektedir. [21] MPS kifozlu hasta serilerinde de, cerrahi yaklaşımdan bağımsız olarak komşu segment problemleri bildirilmiştir. ${ }^{[18,22]}$

MPS'li hastaların cerrahi tedavisi ile ilgili bir diğer problem ise, bu hastalarda anestezi ile ilişkili komplikasyon riskinin yüksekliğidir. Belani ve ark., 30 MPS'li hastaya uygulanan 141 cerrahi girişimde, hastaların yarısında ciddi havayolu obstrüksiyonu, \%21'inde trakeomalazi, \%14'ünde trakeal stenoz rapor etmişlerdir. ${ }^{[23]}$ Ayrıca, birçok hastada odontoid hipoplazisinin bulunması nedeniyle, entübasyonda zorluklar yaşandığı bildirilmiştir. Başka bir çalışmada ise Walker ve ark., MPS'li hastaların anestezisinde ani kardiyak arrest, inme ve pulmoner ödem gibi ciddi komplikasyonlar rapor etmişlerdir. ${ }^{[24]} \mathrm{Bu}$ nedenle, bu hastaların cerrahi öncesi dönemde kardiyoloji, göğüs hastalıkları ve kulak-burun-boğaz bölümleri tarafindan değerlendirilmesi önerilmektedir.

\section{SONUÇ}

Kemik iliği transplantasyonu ve enzim replasman tedavisi ile, MPS hastalarının beklenen yaşam süresi uzamış, yaşam kalitesi anlamlı derecede artmıştır. Ancak, bu sistemik iyileşmeler, kas-iskelet sistemi sorunlarında dikkati çeker bir değişikliğe neden olmamaktadır. 


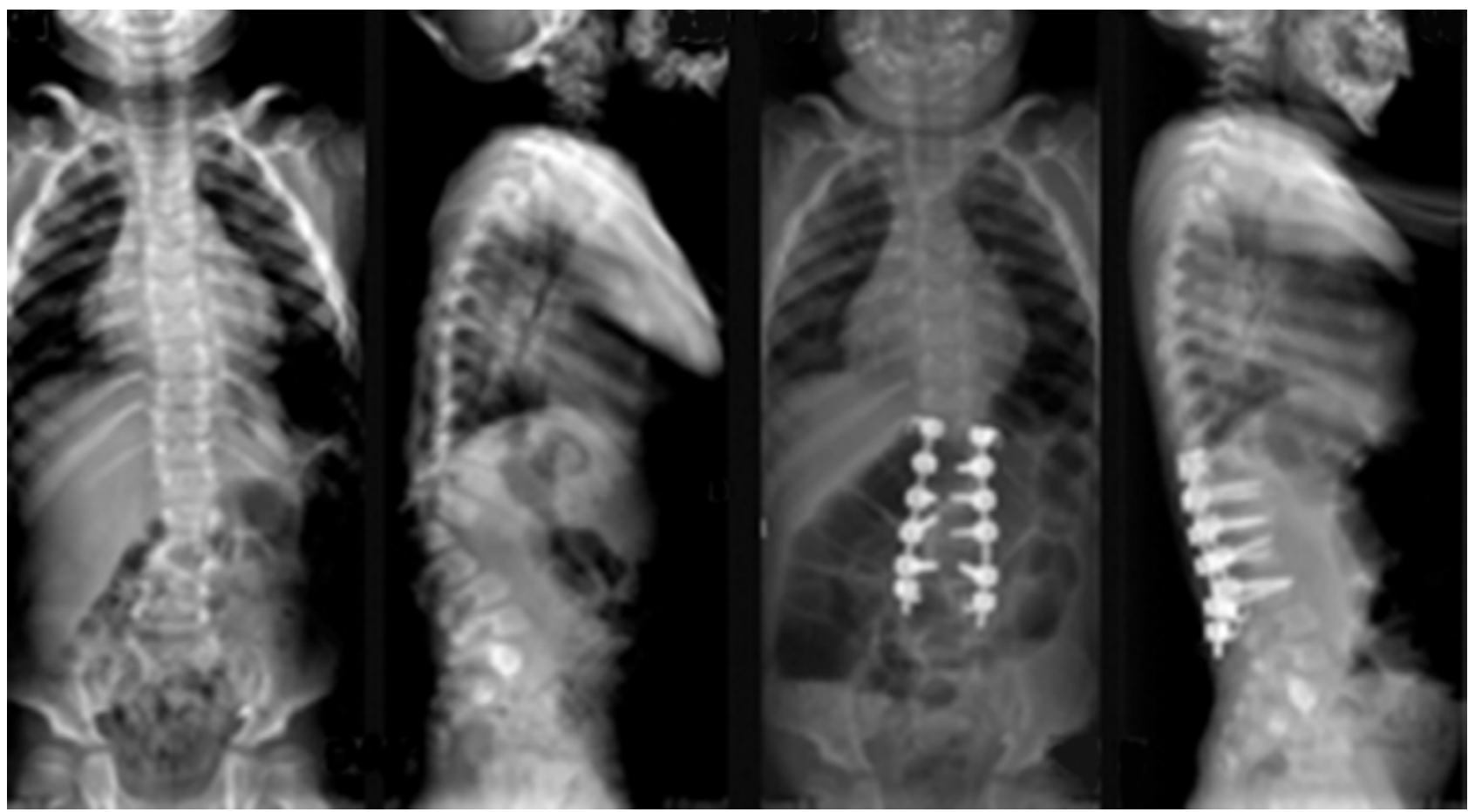

Şekil 2. Beş yaşında erkek, MPS Tip I. Tokrakolomber kifoz nedeniyle posterior enstrümantasyon ve füzyon uygulandı. Beş yıllık takip sonunda başarılı bir klinik ve radyolojik sonuç elde edildi.

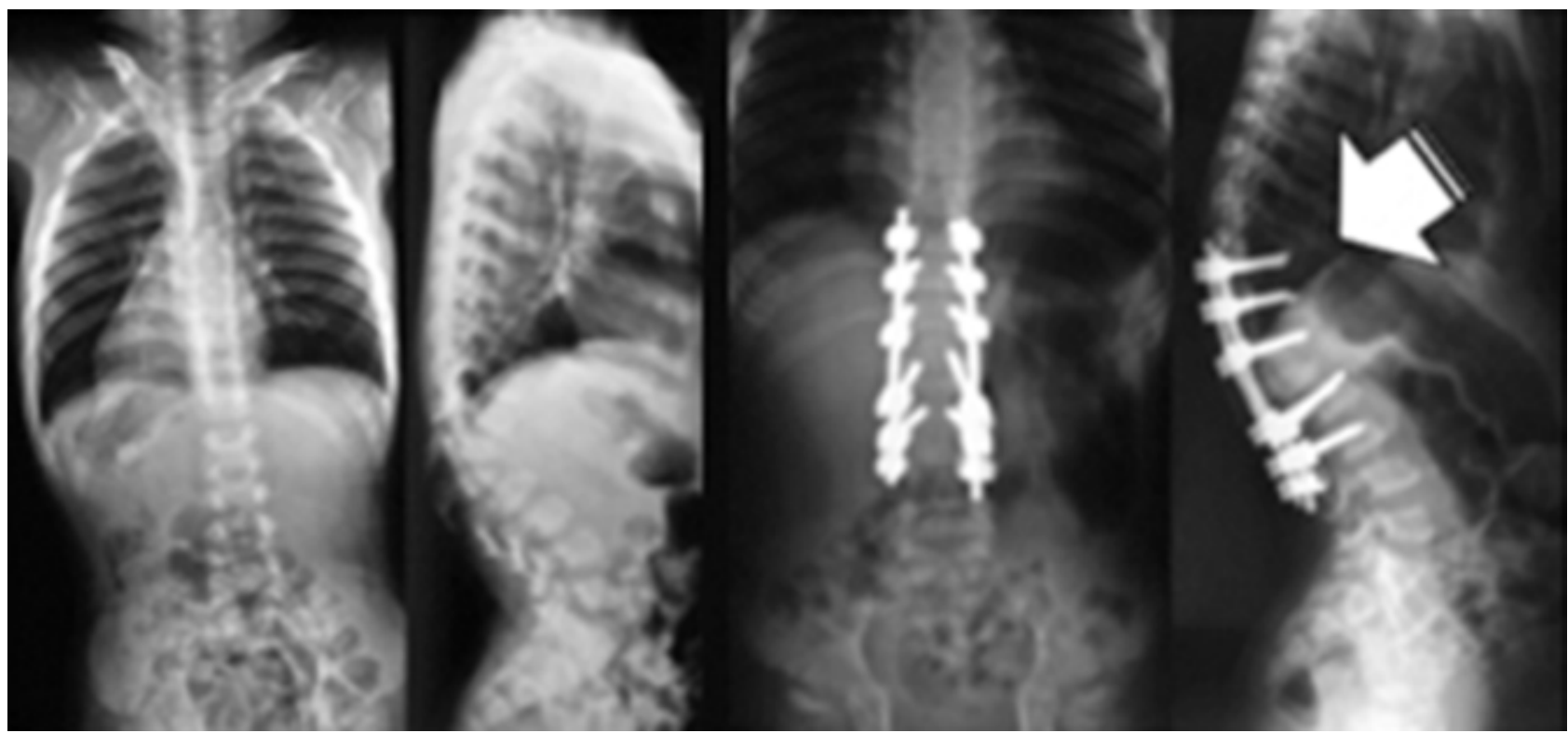

Şekil 3. Yedi yaşında kız hasta, MPS Tip IV. Hastanın cerrahi sonrası dördüncü yılındaki takip grafilerinde prokimal bileşkede kifoz geliştiği görülmektedir.

Hastaların kas-iskelet sistemi bulguları açısından yakın izlemi şarttır. Özellikle kord basısına neden olan oksipitoservikal bölge sorunları ve torakolumbar bileşke kifozu yakından izlenmeli, ilerleme riski bulunan hastalar cerrahi yöntemlerle tedavi edilmelidir. Cerrahi girişimler kısa dönemde çok başarılı sonuçlar verse de, hastalığın doğası gereği, uzun dönem takipte ilave sorunlarla karşılaşma olasılığı yüksektir. Bu nedenle, cerrahi olarak tedavi edilen MPS hastaları büyüme dönemi sonuna kadar yakından izlenmelidir. 


\section{KAYNAKLAR}

1. Baehner F, Schmiedeskamp C, Krummenauer F, Miebach E, Bajbouj M, Whybra C, Kohlschütter A, Kampmann C, Beck $\mathrm{M}$. Cumulative incidence rates of the mucopolysaccharidoses in Germany. J Inherit Metab Dis 2005;28(6):1011-7.

2. Weisstein JS, Delgado E, Steinbach LS, Hart K, Packman S. Musculoskeletal manifestations of Hurler syndrome: longterm follow-up after bone marrow transplantation. J Pediatr Orthop 2004;24(1):97-101.

3. Simonaro CM, Ge Y, Eliyahu E, He X, Jepsen KJ, Schuchman $\mathrm{EH}$. Involvement of the Toll-like receptor 4 pathway and use of TNF-alpha antagonists for treatment of the mucopolysaccharidoses. Proc Natl Acad Sci U S A 2010;107(1):222-7. Crossref

4. Wang RY, Bodamer OA, Watson MS, Wilcox WR; ACMG Work Group on Diagnostic Confirmation of Lysosomal Storage Diseases. Lysosomal storage diseases: diagnostic confirmation and management of presymptomatic individuals. Genet Med 2011;13(5):457-84. Crossref

5. Field RE, Bucannon JAF, Copplemans MG, Aichroth PM. Bone-marrow transplantation in Hurler's syndrome. Effect on skeletal development. J Bone and Joint Surg Br 1994;76:975-81.

6. WraithJE. The first 5 years of clinical experience with laronidase enzyme replacement therapy for mucopolysaccharidosis I. Expert Opin Pharmacother 2005;6(3):489-506.

7. Thomas SL, Childress MH, Quinton B. Hypoplasia of the odontoid with atlanto-axial subluxation in Hurler's syndrome. Pediatr Radiol 1985;15(5):353-4.

8. White KK, Steinman S, Mubarak SJ. Cervical stenosis and spastic quadriparesis in Morquio disease (MPS IV). A case report with twenty-six-year follow-up. J Bone Joint Surg Am 2009;91(2):438-42. Crossref

9. Mut M, Cila A, Varli K, Akalan N. Multilevel myelopathy in Maroteaux- Lamy syndrome and review of the literature. Clin Neurol Neurosurg 2005;107(3):230-5.

10. Tandon V, Williamson JB, Cowie RA, Wraith JE. Spinal problems in mucopolysaccharidosis I (Hurler syndrome). J Bone Joint Surg Br 1996;78(6):938-44.

11. Stevens JM, Kendall BE, Crockard HA, Ransford A. The odontoid process in Morquio-Brailsford's disease. The effects of occipitocervical fusion. J Bone Joint Surg $\mathrm{Br}$ 1991;73(5):851-8.

12. Dede O, Thacker MM, Rogers $\mathrm{KJ}$, Oto $\mathrm{M}$, Belthur MV, Baratela W, Mackenzie WG. Upper cervical fusion in children with Morquio syndrome: intermediate to long-term results. J Bone Joint Surg Am 2013;95(13):1228-34. Crossref
13. Swischuk LE. The beaked, notched, or hooked vertebra: its significance in infants and young children. Radiology 1970;95(3):661-4.

14. Mundada V, D'Souza N. Lumbar gibbus: early presentation of dysostosis multiplex. Arch Dis Child 2009;94(12):930-1. Crossref

15. Dalvie S, Skinner J, Vellodi A, Noorden HH. Mobile thoracolumbar gibbus in Morquio type $A$ : the cause of paraparesis and its management. J Pediatr Orthop B 2001;10(4):328-30.

16. Ebara $\mathrm{S}$, Kinoshita T, Yuzawa $\mathrm{Y}$, Takahashi J, Nakamura I, Hirabayashi H, Uozumi R, Kimura M, Takaoka K.. A case of mucopolysaccharidosis IV with lower leg paresis due to thoraco-lumbar kyphoscoliosis. J Clin Neurosci 2003;10(3):358-61.

17. Dalvie SS, Noorden $\mathrm{MH}$, Vellodi A. Anterior instrumented fusion for thoracolumbar kyphosis in mucopolysaccharidosis. Spine (Phila Pa 1976) 2001;26(23):E539-41.

18. Abelin Genevois K, Garin C, Solla F, Guffon N, Kohler R. Surgical management of thoracolumbar kyphosis in mucopolysaccharidosis type 1 in a reference center. J Inherit Metab Dis 2014;37(1):69-78. Crossref

19. Garrido E, Tomé-Bermejo F, Adams Cl. Combined spinal arthrodesis with instrumentation fort the management of progressive thoracolumbar kyphosis in children with mucopolysaccharidosis. Eur Spine J 2014;23(12):2751-7. Crossref

20. Bekmez S, Demirkiran G, Olgun D, Dede O, Yazici M. Posterioronly Instrumented Fusion for Treatment of Progressive Thoracolumbar Kyphosis in Mucopolysaccharidosis. https:// www.growingspine.org/UserFiles/file/Poster34.ppsx

21. Karatas AF, Dede O, Rogers $K$, Ditro CP, Holmes L, Bober M, Shah SA, Mackenzie WG. Growth-sparing spinal instrumentation in skeletal dysplasia. Spine (Phila Pa 1976) 2013:15;38(24):E1517-26. Crossref

22. Yasin $M N$, Sacho R, Oxborrow NJ, Wraith JE, Williamson JB, Siddique I. Thoracolumbar kyphosis in treated mucopolysaccharidosis 1 (Hurler syndrome). Spine (Phila Pa 1976) 2014;39(5):381-7. Crossref

23. Belani KG, Krivit W, Carpenter BL, Braunlin E, Buckley JJ, Liao JC, Floyd T, Leonard AS, Summers CG, Levine S, et al. Children with mucopolysaccharidosis: Perioperative care, morbidity, mortality, and new findings. J Pediatr Surg 1993;28(3):403-10.

24. Walker RW, Dearlove OR. Anaesthesia for children with mucopolysaccharidoses. Anaesth Intensive Care 1997;25(2):197-8. 